Int. J. Electrochem. Sci., 14 (2019) $8371-8381$

International Journal of

ELECTROCHEMICAL

SCIENCE

$\underline{\text { WWW.electrochemsci.org }}$

\title{
Study on Fe-doped Activation Carbon-based Supercapacitor at
} 4V

\author{
Jie Li, Zhou Xu*, Zhian Zhang* \\ School of Metallurgy and Environment, Central South University, Changsha 410083, China. \\ *E-mail: csuxuzhou@163.com, zza75@163.com
}

doi: $10.20964 / 2019.09 .40$

Received: 9 April 2019 / Accepted: 3 July 2019 / Published: 31 July 2019

Iron impurities will be mixed into the products during the production of supercapacitors due to wear and tear of equipment. So, this paper designs a Supercapacitor system of Fe-doped activated carbon, in a pouch scale, is studied with the use of organic electrolyte (slat of $\mathrm{MeEt}_{3} \mathrm{NBF}_{4}$ in the solvent of propylene carbonate) at $4 \mathrm{~V}$. Gas evolution, from the decomposition of electrode, electrolyte and the binders (sodium carboxymethyl cellulose and polymerized styrene butadiene rubber) is in situ analyzed with the simultaneous analysis of electrochemical signals, when the pouch of supercapacitor was integrated with a gas bag. The addition of $\mathrm{Fe}$ on activated carbon results in the production of $\mathrm{H}_{2}$, $\mathrm{CO}$ and $\mathrm{CO}_{2}$ as the dominant gases with the accelerated rate, while no $\mathrm{CO}$ and $\mathrm{CO}_{2}$ are produced in the absence of Fe. The determination of the origin of gases suggests that salt of $\mathrm{MeEt}_{3} \mathrm{NBF}_{4}$ of electrolyte is firstly decomposed in the absence of Fe. While sodium carboxymethyl cellulose is firstly decomposed in the presence of Fe, due to its hydrophilic property and the structure of electrode sheet. A mode of gas evolution was established as considering processing technology and the hydrophilic properties of materials. The results provide a new insight on the "buckets effect" of supercapacitor that the metal impurities, exhibit much serious negative effect in decomposing components inside device, not limited to the decomposition of electrolyte as previously reported.

Keywords: Supercapacitor; Activated carbon; Organic electrolyte; Gas evolution; High voltage

\section{FULL TEXT}

(C) 2019 The Authors. Published by ESG (www.electrochemsci.org). This article is an open access article distributed under the terms and conditions of the Creative Commons Attribution license (http://creativecommons.org/licenses/by/4.0/). 